\title{
CORRESPONDENCE
}

\section{Ethics of trials}

SIR - The article on the proposed trials of the Medical Research Council (MRC) to investigate supplements in the prevention of neural tube defects (NTD) refers to ethical questions (Nature 16 September) ${ }^{1}$. The MRC trial protocol conflicts with the revised Helsinki Code adopted by the 29th World Medical Assembly in Tokyo in $1975^{2}$.

Dr Nicholas Wald is quoted as believing that a trial is ethical if "the likely good of the treatment" balances "the possible harm", implying that harm to one set of patients can be offset by benefit of another set, or of society. The revised code says (paragraph I.5): "Concern for the interests of the subject must always prevail over the interests of science and society". Informed consent does not affect this obligation (paragraphs II.6 and II.4).

The judgement in the Nuremberg trial of doctors for unethical human experimentation in 1947 said: "The protagonists of the practice of human experimentation justify their views on the basis that such experiments yield results for the good of society" judgement enunciated the Nuremberg Code which was replaced by the Helsinki Code of the World Medical Association in 1964, revised in 1975 .

Paragraph II.3 of the revised code says: "In any medical study every patient - including those of a control group, if any - should be assured of the best proven diagnostic and therapeutic method"'. The MRC trial is proposing to supplement a random half of patients with folate regardless of whether they are folate deficient, although techniques for assay of folate status are available and folate deficiency can be remedied in most patients.

Paragraph $I .1$ requires all research involving human subjects to be preceded by "'adequately performed laboratory and animal experimentation". Folate deficiency in animals is reported to cause fetal resorption, low birthweight, small litter size, stillbirths and polymorphic malformations involving all body systems, as would be expected from folate's biochemical role in DNA synthesis. Folate deficiency delays development of the central nervous system in young children and is associated with mental illness in adults ${ }^{4}$. Paragraph I.9 requires subjects of human experimentation to be informed of " potential hazards of the study".

Folate is only one of over 30 nutrients known to be essential for normal embryonic growth. The comparative importance of different nutrient deficiencies in increasing the risk of malformations will only be discovered by extensive biochemical measurement of nutrient status. Randomized trials will never produce the answer if only because trials of 30 different nutrients at only two different levels of supplementation would require $3^{30}$ trials. It can be argued that the MRC trial, because it will give no information on the prevalence of any nutrient deficiency, contravenes paragraph I. 4 of the code which requires "the importance of the objective"' to be in proportion to the inherent risk to the individual. The $£ 300,000$ would be better spent on well-planned biochemical measurements of the tissues or blood of women who have had babies with neural tube defects or some other malformations.
The MRC trial protocol contravenes paragraph $\mathrm{I} .12$ of the code which says: "The research protocol should always contain a statement of the ethical considerations involved and should indicate that the principles enunciated in the present Declaration are complied with."

Arthur WynN

Highgate,

London N6, UK

1. Nature 299, 198 (1982).

World med. J. 24, 76 (1977)

3. United States V. Karl Brandt in Experimentation with Human Beings (ed. Katz, J.) 305-306 (Russell-Sage, New York, 1972).

4. Botez, M.I. \& Reynolds, E.H. (eds) Folic Acid in Neurology, Psychiatry, and Internal Medicine (Raven, New York, 1979).

\section{CAB taxed}

SIR - Many eyes must have been rubbed (and job applications drafted) when they read that employees of the Commonwealth Agricultural Bureaux no longer pay income tax (Nature, 14 October, p.572), and less self-interested souls must have wondered about the benefit of this to CAB member governments. The benefit lies in what amounts to a 30 per cent cut in taxable salary for $\mathrm{CAB}$ employees. A tax consultant works out what employees would normally pay in tax to the UK government, then hands this amount back to CAB. Take-home pay is thus virtually the same as before CAB's internationalization.

Edinburgh, UK

Allan Rostron

\section{First to use?}

SIR - In the article entitled "Vatican and the bomb" (Nature 4 November, p.2) you imply that the group convened by the Pontifical Academy in September called for a "declaration of no first use" of nuclear weapons. This is not true.

An earlier draft of the document, prepared by a group of which I was not a member, did indeed "call upon all nations to pledge never to be the first to use nuclear weapons"'. Many of those present at the final meeting, including myself, objected strongly to this wording on precisely the grounds you state in your article. The words "to pledge" were therefore omitted from this passage in the final document. This was signed by all the participants, and they included all but one of the fourteen who had prepared the earlier draft.

The final version of the document does not contain any suggestion that nations should make a "declaration of no first use" of nuclear weapons.

Sir Andrew Huxi.ey President of the Royal Society

The Royal Society,

London SW1, UK

The distinction is important but not, without this explanation, readily apparent.

EDITOR. Nature

\section{No to boycott}

SIR - In responding to Dr Rowan-Robinson's appeal to end British participation in astronomy in South Africa (Nature 14 October, p.574) I must first declare an interest. I was one, if not the first, to propose a unification of observatories in South Africa at a single site at Sutherland and a leading activist in site selection and site testing. I quit British employ in South Africa - with the greatest regret - as Dr Rowan-Robinson would evidently wish others to do, in the expectation that judging by the contemporary of ficial climate I might be deprived of observational opportunities. The establishment of the observatory at Sutherland was a subsequent reversal of policy. Sutherland is a very good site, comparable with those in Chile and superior to those in Australia. Although less well equipped than Siding Spring it offers to the observer relatively long runs at telescopes. Speaking from an experience of 30 years in telescope scheduling, I am certain that these are very often more productive, pound for pound and night for night than short runs on larger telescopes and permit greater flexibility in the choice of programmes. The facilities afforded by the site would be very hard to replace.

As to the question whether British participation condones or encourages apartheid this is more complex than would appear at first sight. Many of the actions of the South African Government are abhorrent to the international community. Boycotts of the type proposed are usually ineffective. Indeed some of the extreme right wing of the Nationalist party might be only too glad to see a diminution of the cultural influence of the English language and traditions. Such a boycott would primarily be a blow to a considerable section of the population who wish to see significant political changes. The South African Government does have a genuine problem of terrorist activity presumably largely inspired by the Soviet Union which seeks to replace one tyranny by another and to gain control of the crucial oil route round the Cape and the strategic minerals of which southern Africa is the only source available to the free world. It is the hope of all reasonable men that political change will come peacably and that many thousands of innocent and hard working people will not be sacrificed in salving the consciences of those remote from the scene of action.

I believe that the best hope for a peacable solution is to increase rather than decrease cultural links from abroad. In a small way the present influx of scientific visitors promotes this. As to Sutherland itself, it is a dreadful location for the coloured people (there are almost no Bantu in the area) but at the observatory there are six coloured employees with good jobs and good housing. This is not much but it is a positive step towards ameliorating the lot of one section of the population which as far as I could judge from a recent visit is enjoying a period of striking economic advance.

Department of Astronomy,

University of Texas at Austin,

Texas, USA 